\title{
Loneliness, Social Anxiety and Psychological Well-Being in Relation to Internet Addiction among Women College Students
}

\author{
Divya Prabha. $S^{1}$, Sujaritha Magdalin ${ }^{2}$
}

\section{ABSTRACT}

The study was done to understand the loneliness, social anxiety and psychological well-being in relation to internet addiction among women college students. The research hypotheses of the study were as follows: 1 . There will be no significant relationship among loneliness, social anxiety and psychological well-being on internet addiction among women college students; 2 . There will be no significant relationship between age and internet addiction among Women college students;. 3. There will be no significant difference between type of internet users on loneliness, social anxiety, psychological well-being and internet addiction among Women college students. The study was ex post-facto in nature, and cross sectional design was used. Purposive sampling strategy was adopted. The sample comprised of 285 Women college students from Chennai city. The age range of the sample was from 17 to 26 years. Study procedures included the administration of the following measures (i).Davis Online Cognition Scale (DOCS) (Davis, 2001), (ii). UCLA Loneliness Scale (Russell, 1996), (iii). Social Anxiety Questionnaire (SAQ) (Caballo, Salazar, Irurtia, Arias and CISO-A Research Team, 2012) and (iv). PGI General Well-being Measure (Verma \& Verma, 1974). Pearson's Correlation coefficient and ' $t$ ' test were computed to test the hypotheses. Results are discussed in the light of the findings of the study.

Keywords: Loneliness, Social Anxiety, Psychological Well-being, Internet Addiction, women college students

The internet is an exciting new medium that is evolving into an essential part of everyday life all over the world and it is a widely recognized medium for information exchange, academic research, entertainment, communication and commerce (Widyanto \& Griffiths, 2006; Douglas et al., 2008; Byun et al., 2009). Although the positive aspects of the Internet have been readily praised, there is a growing amount of literature on the negative side of its excessive and

\footnotetext{
${ }^{1}$ Ph.D Research Scholar, Bharathiar University, Coimbatore, India

${ }^{2}$ Associate Professor \& Head, Dept of Psychology, Presidency College, Chennai, India.

*Responding Author

(C) 2016, D Prabha, S Magdalin; licensee IJIP. This is an Open Access Research distributed under the terms of the Creative Commons Attribution License (http://creativecommons.org/licenses/by/2.0), which permits unrestricted use, distribution, and reproduction in any Medium, provided the original work is properly cited.
} 


\section{Loneliness, Social Anxiety and Psychological Well-Being in Relation to Internet Addiction among Women College Students}

pathological use (Beard, 2005; Frangos \& Frangos, 2009). Some researches point out that excessive and ill use of the internet will result in the withdrawal of the individual from friends, family, and lead to behavioural or personal disorders. (Yellowlees \& Marks, 2005; Kim et al, 2005; Amiel \& Sargent, 2004; Nie \& Erbring, 2008).In particular, Internet is the representative term of adolescents. This could be natural since this group of teenagers is easily attracted to this medium. According to a recent study, Internet use among teenagers reached $90.6 \%$, which was much higher than among people in their 30s. The study also suggested that college students were becoming more avid users of the Internet. (Korea Network Information Center, 2002).

Adolescents are indiscriminately exposed to the Internet although they do not have the ability to judge its positive and negative aspects. Media reports about the growing side effects of Internet use, easy access to pornography, and even criminal activities have caused much psychological panic among parents. (Lee, Lee, Kim, \& Oh, 2000). Internet overuse and abuse has been related to many adverse effects. Internet addiction has repeatedly been linked to increased levels of depression, loneliness, stress, and sadness (Morahan-Martin \& Schumacher, 2000; Whang, Lee, \& Chang, 2003). Loytsker and Aiello (1997) found that higher levels of proneness to boredom, loneliness, social anxiety, and private self-consciousness all predict internet addiction. The negative influence of Internet use on psychological well-being has been revealed by many researchers. In fact, these social concerns have become global issues. The time has come for society to come up seriously with ways to deal with Internet use and addiction among adolescents. Thus the purpose of this study was to study Loneliness, Social Anxiety and Psychological Well-being in relation to Internet Addiction among women college students.

\section{METHODOLOGY}

The study was ex post-facto in nature, and cross sectional design was used. Purposive sampling strategy was adopted to draw sample for the study.

\section{Participants}

The sample was comprised of 300 women college students from different colleges in Chennai city. Out of 300, 15 data were excluded due to incomplete information. Thus, 285 students' responses were included for final analysis. The age of the sample ranged from 17 to 26 years.

\section{Materials and Procedure}

The instrumental tools used in this study were as follows:

Internet addiction was measured using Davis Online Cognition Scale (DOCS; Davis, 2001). This is a 36-items self-report inventory measured on a 7-point Likert type scale. It was used to identify dependents and non-dependents. It is determined by four indicators: impulsivity, loneliness/depression, distraction, and social comfort. Each of these indicators represents a subscale of the OCS, and were found to have moderate to high internal consistency ( $\alpha$ s range 


\section{Loneliness, Social Anxiety and Psychological Well-Being in Relation to Internet Addiction among Women College Students}

from .77 to .87). Overall, the scale has been found to have high internal consistency with Chronbach's $\alpha$ of 0.94 . The predictive validity, convergent validity, discriminate validity were utilized to establish validity.

Loneliness was measured using University of California, Los Angeles (UCLA) Loneliness Scale (Russell, 1996). This is a 20-item self-report inventory measured on a 4-point scale. The measure was highly reliable, both in terms of internal consistency (coefficient a ranging from.89 to .94) and test-retest reliability over a 1-year period $(r=.73)$. The convergent validity and construct validity were utilized to establish validity.

Social anxiety was measured using Social Anxiety Questionnaire (SAQ; Caballo et.al., 2012). This is a 30-item self-report questionnaire measured on a 5-point scale. It has five factors (subscales): (1) Speaking in public/Talking with people in authority, (2) Interactions with the opposite sex, (3) Assertive expression of annoyance, disgust or displeasure, (4) Criticism and embarrassment, and (5) Interactions with strangers. Each subscale consists of 6 items distributed randomly throughout the questionnaire. There is a score for each subscale and an overall score for the questionnaire as a whole. The internal consistency estimates (Cronbach's $\alpha$ ) of the SAQA30 total score are high (from .92 to .93), and from moderate to high for its subscales (from .75 to .92). The reliability of the questionnaire (Guttman split-half reliability) is high (from .90 to .93). The convergent validity was utilized to establish validity.

Psychological well-being was measured using PGI General Well-being Measure (Verma \& Verma, 1989). The scale consisted of 20 items organized in domains namely physical (e.g. feeling bothered by illness or pain), mood (e.g. feeling cheerful most of the time),anxiety (e.g. feeling useful/wanted)of five items each. Each item is rated on a four- point scale indicating personal frequency of occurrence (not at all, rarely, often or most of the time, frequency or all the time). Higher total and domain- specific scores indicate higher levels of well-being. The splithalf coefficient of reliability corrected by Kudar Richardson correlation was found to be .98 (Verma, Dubey and Gupta, 1983). It is found to have satisfactory validity and highly significant reliability.

\section{Procedure}

Prior permission was obtained from the educational institutions to meet the college students. In each college a particular time was set aside for all the students to respond to the questionnaire and the students were instructed not to discuss the items or to collaborate.

\section{Data analyses}

Karl Pearson's Co-efficient Correlation and t-test were used to assess the significance of the difference between the variables. 


\section{RESULTS}

Pearson's correlation coefficient was computed to assess the relationships among Internet Addiction, Loneliness, Social Anxiety, Psychological Well-being and age and also t-test was computed to assess the significant difference between the type of users (late night users and non late night users) of Women college students on Internet addiction, loneliness, social anxiety and psychological well-being. The following tables show the results of the analysis of the variables used in the study.

Table 1: Mean and standard deviations of the variables used in the study

\begin{tabular}{|l|l|l|l|}
\hline Variables & N & M & SD \\
\hline Internet addiction & 285 & 111.08 & 35.06 \\
\hline Loneliness & 285 & 21.03 & 12.46 \\
\hline Social anxiety & 285 & 82 & 20.71 \\
\hline Psychological well-being & 285 & 10.42 & 5.12 \\
\hline Age & 285 & 18.26 & 0.94 \\
\hline
\end{tabular}

Table 2: Correlations between Internet addiction and Loneliness, Social Anxiety, Psychological Well-being among women college students

\begin{tabular}{|l|c|}
\hline \multicolumn{1}{|c|}{ Variables } & Internet addiction \\
\hline Loneliness & .014 (NS) \\
\hline Social anxiety & .07 (NS) \\
\hline Psychological well-being & -.102 (NS) \\
\hline Age & $-.086(\mathrm{NS})$ \\
\hline
\end{tabular}

NS - Not Significant

It is inferred from table 2 that the Internet addiction in relation to Loneliness, Social Anxiety and Psychological well-being were not found to be significant among women college students. Age and Internet addiction were not related among women college students. Hence, hypotheses which stated that there will be no significant relationship between Internet addiction and Loneliness, Social Anxiety, Psychological Well-being among women college students is accepted. 
Loneliness, Social Anxiety and Psychological Well-Being in Relation to Internet Addiction among Women College Students

Table 3: Difference between type of Internet users (Late night users-after 09:00Pm and Non late night users) on Internet addiction, Loneliness and Psychological Well-being among women college students.

\begin{tabular}{|c|c|c|c|c|c|c|}
\hline Variables & $\begin{array}{c}\text { Type of } \\
\text { Internet } \\
\text { users }\end{array}$ & $\mathbf{N}$ & Mean & SD & SED & 't' value \\
\hline \multirow{2}{*}{$\begin{array}{c}\text { Internet } \\
\text { Addiction }\end{array}$} & $\begin{array}{ll}\text { Late night } \\
\text { users }\end{array}$ & 134 & 116.37 & 32.74 & \multirow{2}{*}{4.20} & \multirow{2}{*}{$2.55^{*}$} \\
\hline & $\begin{array}{l}\text { Non late night } \\
\text { users }\end{array}$ & 134 & 105.62 & 36.00 & & \\
\hline \multirow{2}{*}{ Loneliness } & $\begin{array}{ll}\text { Late night } \\
\text { users }\end{array}$ & 134 & 19.72 & 12.34 & \multirow{2}{*}{1.53} & \multirow{2}{*}{$\begin{array}{l}1.53 \\
\text { (NS) }\end{array}$} \\
\hline & $\begin{array}{l}\text { Non late night } \\
\text { users }\end{array}$ & 134 & 22.08 & 12.82 & & \\
\hline \multirow{2}{*}{ Social anxiety } & $\begin{array}{ll}\text { Late } & \text { night } \\
\text { users }\end{array}$ & 134 & 82.48 & 19.71 & \multirow{2}{*}{2.49} & \multirow[b]{2}{*}{$\begin{array}{l}0.44 \\
\text { (NS) }\end{array}$} \\
\hline & $\begin{array}{l}\text { Non late night } \\
\text { users }\end{array}$ & 134 & 81.38 & 21.03 & & \\
\hline \multirow{2}{*}{$\begin{array}{l}\text { Psychological } \\
\text { well-being }\end{array}$} & $\begin{array}{ll}\begin{array}{l}\text { Late } \\
\text { users }\end{array} & \\
\end{array}$ & 134 & 10.71 & 5.18 & \multirow{2}{*}{0.624} & \multirow{2}{*}{$\begin{array}{l}0.91 \\
\text { (NS) }\end{array}$} \\
\hline & $\begin{array}{l}\text { Non late night } \\
\text { users }\end{array}$ & 134 & 10.14 & 5.03 & & \\
\hline
\end{tabular}

* Significant at 0.05 level; NS - Not Significant

Table 3 presents the significant difference between type of Internet users (late night users -after 09:00 Pm and non late night users) on Internet addiction, Loneliness, Social Anxiety and Psychological Well-being among women college students. There was a significant difference between type of Internet users (late night users and non late night users) on Internet addiction among women college students at 0.05 level of significance and late night users were found to be more addicted to Internet than non late night users. On the other hand, there were no significance differences between type of Internet users (late night users and non late night users) on Loneliness, Social Anxiety and Psychological Well-being among women college students. Hence, hypotheses which stated that there will be no significance difference between type of Internet users (late night users- after 09:00 Pm and non late night users) on Internet addiction among women college students is partially accepted.

\section{DISCUSSION}

This study aimed to assess the relationship of Loneliness, Social anxiety Psychological Wellbeing, age and type of internet users on Internet addiction among women college students. The results of this study indicate that the Internet addiction in relation to Loneliness, Social anxiety and Psychological well-being were not found to be significant among women college students.

(C) The International Journal of Indian Psychology, ISSN 2348-5396 (e)| ISSN: 2349-3429 (p) | 42 


\section{Loneliness, Social Anxiety and Psychological Well-Being in Relation to Internet Addiction among Women College Students}

Research on internet addiction demonstrated that the greater use of the internet is associated with some social and psychological variables such as, declines in the size of social circle, depression, loneliness (Kraut et al., 1998), lower self-esteem and life satisfaction (Ko, Yen, Chen et al., 2005), sensation seeking (Lin \& Tsai, 2002) and poor mental health (Yang, 2001; Young \& Rogers, 1998). Many previous research studies have been shown to be in contradictory with the current study findings. However, Ahmed and Alshwai (2014) found that there were no significant differences in the variables of Internet addiction and Loneliness. On the other hand, a significant difference was observed between Internet addiction and feeling of Loneliness. According to Kraut and his colleagues (1998), they had reported that increases in loneliness and depression may have nothing to do with Internet use. According to the present study, may be the participants' lack of social contacts (such as new college students) might use the Internet to deal with Loneliness, Hence, Loneliness that leads to Internet use, but not vice versa. Therefore, Internet is a social technology used for communication with individuals and groups and it was associated with declination in Loneliness.

When examining the Social anxiety in relation to Internet addiction, it was found that there was no significant relationship between Internet addiction and Social anxiety among women college students. Erwin et al. (2004), who also found that the most anxious individuals did not find the Internet to be a significant provider of social support. It is likely that these individuals require more extensive support than what can reasonably be gained online.

When analyzing Psychological well-being in relation to Internet addiction, it was found that there was no significant relationship between Internet addiction and Psychological well-being among women college students. Psychological well-being or mental health is not merely an absence of mental disorder, but it is a state of mental, intellectual, and psychological maturity of an individual. Pandya and Korat (2015) stated that there was no significant relationship between Internet addiction and Psychological well-being among youths. Another theoretical approach is that Internet use expands, rather than displaces, possibilities to contact peers, and thus enhances feelings of self-esteem and well-being (Morgan \& Cotten, 2003; Valkenburg \& Peter, 2007). In accordance with this, cross-sectional survey studies have shown that college students' Internet use was directly (Morgan \& Cotten, 2003) and indirectly (LaRose, Eastin, \& Gregg, 2001) related to less depression. Furthermore, studies have revealed that Internet use can lead to online relationship formation and thereby to more social support (Nie \& Erbring, 2000; Wellman, Quan-Haase, Witte, \& Hampton, 2001; Wolak et al., 2003), which may subsequently lead to less internalizing problems.

\section{DEMOGRAPHIC FACTORS IN RELATION TO INTERNET ADDICTION}

In the present study, the results indicate that the age was not related to Internet addiction among Women college students. The age group of the sample ranged from 17 to 26 years and the mean 


\section{Loneliness, Social Anxiety and Psychological Well-Being in Relation to Internet Addiction among Women College Students}

of age group were 18.26. Waldo (2014) was found that there was no significance difference between age and Internet addiction. In other words, regardless of one's age (15-19) one may develop Internet addiction.

Late night users (after 09:00 Pm) were found to be more addicted to Internet than non late night users among women college students. So it is understood that the Internet addiction was found to be higher in students who used the internet late at night (that is after 9:00 p.m.) compared to students who did not use the Internet late at night (that is, day and evening use but not after 9:00 p.m.). On the other hand, loneliness, social anxiety and psychological well-being on type of Internet users (late night users and non late night users) were not found to be significant in the present study among women college students.

Over the past decade a great deal has been published regarding Internet addiction and compulsive use of the Internet. While preliminary in nature, many researches suggests that addictive use of the Internet has created significant psychological and social problems though the present study was contradictory to many research studies and inconsistent with the three variables namely Social anxiety, Loneliness and Psychological well-being in relation to Internet addiction, but further awareness must be created among the students on Internet addiction. While acknowledging that more research is needed to clarify this and related issues, the consistent theme in the literature to date is that Internet addiction, at whatever level, is indeed, a real problem; a problem, that with the increase of access to the Internet, may only get worse. Rather than blaming the victim (i.e., the addict) and establishing overly restrictive laws and regulations, public policy should focus on promoting the healthy and safe use of the Internet. To pursue such effective recovery programs, continued research is needed to better understand the underlying motivations of Internet addiction.

Further, educational programs about safe Internet use, harm minimization, prevention programs, recovery centers, support groups, and the integration of training workshops specializing in Internet addiction must be activated and encouraged to address the emergence of this problem, especially among the school students in the society. While a student's education must proceed using the most up to date and appropriate technology available, the dangers of these technologies must be recognised, studied, examined, and interventions developed to maximize the utility of these technologies while minimising the potential harm to the individual as well as society.

\section{Acknowledgments}

The author appreciates all those who participated in the study and helped to facilitate the research process.

\section{Conflict of Interests}

The author declared no conflict of interests. 


\section{Loneliness, Social Anxiety and Psychological Well-Being in Relation to Internet Addiction among Women College Students}

\section{REFERENCES}

Ahmed, K. I., \& Alshawi, S.S. (2014). The Relationship between Internet Addiction and Loneliness among Girls of Faculty of Physical Education\University of Baghdad. International Journal of Advanced Sport Sciences Research, 2 (3), 235-242.

Amiel T. And Sargent S.L.(2004). Individual differences in Internet usage motives. Computer in human behaviour ;(20):711-726. doi:10.1016/j.chb.2004.09.002

Beard, K.W., (2005), „Internet addiction: a Review of current assessment techniques and potential assessment questions ${ }^{e e}$, Cyber Psychology \& Behavior, 8, pp. 7-14.

Byun, S., Ruffini, C., Mills, J.E., Douglas, A.C., Niang, M., Stepchenkova, S., Lee, S.K., Loutfi, J., Lee, J-K., Atallah, M., Blanton, M., (2009), „Internet Addiction: Meta synthesis of1996- 2006. Quantitative Researche, Cyber Psychology \& Behavior, 12, pp. 203-207 Retrieved from http://www.ncbi.nlm.nih.gov/pubmed/19072075

Caballo, V. E., Salazar, I. C., Irurtia, M. J., Arias, B.,and CISO-A Research Team. (2012). Social Anxiety Questionnaire (SAQ-A30) . Measurement Instrument Database for the Social Science.

Chou, C., \& Hsiao, M. C. (2000). Internet addiction, usage, gratification, and pleasure experience: the Taiwan college students ${ }^{\text {ee }}$ case. Computers and Education, 35, 65-80.

Chou, C., Chou, J., \& Tyan, N. N. (1999). An exploratory study of Internet addiction, usage and communication pleasure: The Taiwan's case. Journal of Educational Telecommunications, 5(1), 47-64.

Davis R. A.(2001). A cognitive behavioural model of pathological internet use. Journal of computer in Human Behavior; (17): 181- 195

Douglas, A.C., Mills, J.E., Niang, M., Stepchenkova, S., Byun, S., Ruffini, C., Lee, S.K., Loutfi, J., Lee, J-K., Atallah, M., Blanton, M., (2008), „Internet addiction: Meta synthesis of qualitative research for the decade 1996-2006 ${ }^{\mathrm{ee}}$, Computers in Human Behavior, 24, pp. 3027- 3044 doi:10.1016/j.chb.2008.05.009

Erwin, B.A., Turk, C.L., Heimberg, R.G., Fresco, D.M.,\& Hantula, D.A. (2004). The Internet: Home to a severe population of individuals with social anxiety disorder. Journal of Anxiety Disorders, 18, 629-646.

Frangos, C.C., Frangos, C.C., (2009), Internet Dependence in College Students from Greecee, European Psychiatry, 24 (Suppl 1), S419. Doi : 10.1016/S0924-9338(09)70652-2.

Griffiths, M. D. (2000). Does Internet and computer “addiction” exist? Some case study evidence. Cyberpsychology and Behavior, 3(2), 211-2181. doi: 10.1089/109493100316067

Kandell, J. J. (1998). Internet addiction on campus: the vulnerability of college students. CyberPsychology and Behaviour, 1(1), 11-17.

Kim K., Ryu E., Chon M.(2005). Internet addiction in Korean adolescents and its relation to depression and suicidal ideation: A questionnaire survey. International Journal of Nursing studies; 34(2): 185- 192. 


\section{Loneliness, Social Anxiety and Psychological Well-Being in Relation to Internet Addiction among Women College Students}

http://www.sciencedirect.com/science/article/pii/S002074890500043X

Ko, C. H., Yen, J. Y., Chen, C. C. et al., 2005. Gender differences and related factors affecting online gaming addiction among Taiwanese adolescents. Journal of Nervous \& Mental Disease, 193, 273-277.

Kraut, R., Patterson, M., Lundmark, V., et al. (1998), "Internet paradox: A social technology that reduces social involvement and psychological well-being?", American Psychologist, Vol.53, pp.1017-31.

LaRose, R., Eastin, M. S., Gregg, J. (2001). Reformulating the Internet paradox: Social cognitive explanations of Internet use and depression. Journal of Online Behavior, 1 (2).

Retrieved May 1, 2006 from: http://www.behavior.net.proxy.lib.ohiostate.edu/JOB/v1n1/paradox.html

Lee, S.H., Lee, S.Y., Kim, E.J., \& Oh, S.G. (2000). Internet addiction of adolescents and children education. Samsung life public welfare foundation.

Lin, S. S. J., \& Tsai, C. C., 2002. Sensation seeking and internet dependence of Taiwanese high school adolescents. Computers in Human Behavior, 18, 411-426.

Loytsker, J., \& Aiello, J.R. (1997). Internet addiction and its personality correlates. Poster presented at the annual meeting of the Eastern Psychological Association, Washington, DC, April 11, 1997.

Morahan-Martin, J., \& Schumacher, P. (2000). Incidence and correlates of pathological Internet use among college students. Computers in Human Behavior, 16, 13-29.

Morgan, C., \& Cotten, S. R. (2003). The relationship between Internet activities and depressive symptoms in a sample of college freshmen. Cyber Psychology and Behavior, 6, 133e142.

Nie, N. H., \& Erbring, L. (2000). Internet and society: A preliminary report. Stanford, CA: Stanford Inst. of Quant. Study Soc.

Pandya, M., \& Korat, N., (2015). Internet Addiction and Psychological Well-being among Youths of Rajkot District. The International Journal of Indian Psychology, 2 (2).

Russell D, Peplau LA, Cutrona CE. (1980). The revised UCLA Loneliness Scale: Concurrent and discriminate validity evidence. Journal of Personality and Social Psychology, 39: 472-480.

Valkenburg, P. M., \& Peter, J. (2007). Online communication and adolescent well-being: testing the stimulation versus the displacement hypothesis. Journal of Computer Mediated Communication, 12, 1169e1182.

Verma, S.K. \& Verma, A. (1989). PGI General Wellbeing Measure. Lucknow: Ankur Psychological Agency.

Verma, S.K., Dubey, B.L., \& Gupta, D. (1983). P.G.I General Well-being Scale, Indian Journal of Clinical Psychology, 10, 299-304.

Wellman, B., Quan-Haase, A., Witte, J., \& Hampton, K. (2001). Does the Internet increase, decrease, or supplement social capital? Social networks, participation, and community commitment. American Behavioral Scientist, 45,436e455. 


\section{Loneliness, Social Anxiety and Psychological Well-Being in Relation to Internet Addiction among Women College Students}

Whang, L. S. M., Lee, S., \& Chang, G. (2003). Internet over-users' psychological profiles: a behavior sampling analysis on internet addiction. CyberPsychology \& Behavior, 6(2), $143-150$.

Widyanto, L., Griffiths, M., (2006), „Internet Addiction“e: A Critical Reviewe, InternationalJournal of Mental Health and Addiction, 4, pp. 31-51. DOI: 10.1007/s11469006- 9009-9

Wolak, J., Mitchell, K. J., \& Finkelhor, D. (2003). Escaping or connecting? Characteristics of youth who form close online relationships. Journal of Adolescence, 26, $105 \mathrm{e} 119$.

Yang, C. K., 2001. Sociopsychiatric characteristics of adolescents who use computers to excess. Acta Psychiatrica Scandinavica, 104, 217-222.

Yellowlees P. M., Marks, S.(2005) Problematic Internet use or internet addiction? Computer in Human Behavior; 23(2): 1447-1453. doi:10.1016/j.chb.2005.05.004.

Young, K. (1998). Caught in the net: How to recognize the signs of internet addiction and a winning strategy for recovery. New York: John Wiley \& Sons.

Young, K. S., \& Rogers, R. C. (1998). The relationship between depression and Internet addiction. Cyberpsychology and Behavior, 1(1), 25-28.

How to cite this article: D Prabha, S Magdalin (2016), Loneliness, Social Anxiety and Psychological Well-Being in Relation to Internet Addiction among Women College Students, International Journal of Indian Psychology, Volume 3, Issue 4, No. 63, ISSN 2348-5396 (e), ISSN: 2349-3429 (p), DIP: 18.01.099/20160304, ISBN: 978-1-365-32518-2 